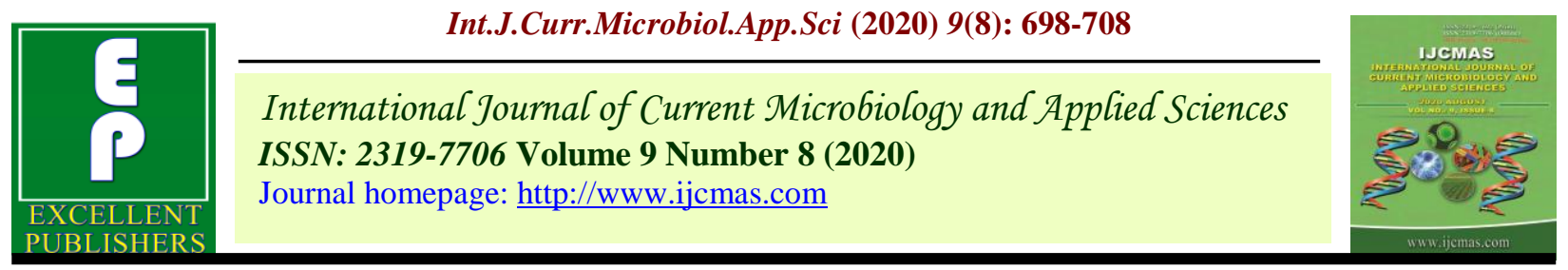

Review Article

https://doi.org/10.20546/ijcmas.2020.908.076

\title{
Dichogamy and its Relevance in Fruit Crops: An Overview
}

\author{
Prachi Pant, V. P. Singh*, Rashmi Panwar and Rajkumar Jat \\ Department of Horticulture, College of Agriculture, G. B. Pant University of Agriculture and \\ Technology, Pantnagar, U.S. Nagar-263145 (Uttarakhand), India \\ *Corresponding author
}

\section{A B S T R A C T}

\section{Keywords \\ Dichogamy, Types of dichogamy, Function of dichogamy, Fruit crops}

\begin{tabular}{l} 
Article Info \\
\hline Accepted: \\
10 July 2020 \\
Available Online: \\
10 August 2020 \\
\hline
\end{tabular}

Fruit crops, mostly perennial, are highly heterozygous with a complex genetic nature and several cross-breeding barriers. Among the various evolutionary mechanisms of floral behavior reported in fruit crops, dichogamy is one of the most important mechanisms with the most prevalent also. Dichogamy refers to the maturation of sex organs at different times in plants. It is mainly divided into two main types; protoandry and protogyny. However, various other classifications have also been suggested by the scientists in flowering plants which further elaborated the mechanism. These were based on the basis of floral elements (intrafloral and interfloral), degree of stamen and pistil separation (complete and incomplete), degree of plant synchronization (asynchronous, hemisynchronous and synchronous) and by the time interval between stamen and pistil emergence. some special types viz., duodichogamy, heterodichogamy and PDSD were also exhibited by different fruit crops. Dichogamy promotes outcrossing even in hermaphrodite species which controls genetic transmission within and among the population. The present paper reviewed the types and characteristics of dichogamy observed in various fruit crops. The comprehensive knowledge of it is mandatory for good fruit setting with quality and higher yield along with further improvement in fruit species.

\section{Introduction}

Fruit crops, most of them being perennial, are highly heterozygous in nature. Fruitfulness and improvement both are greatly restrained by complex genetic nature and several crossability barriers. Various mechanisms, act as crossing barriers in fruit crops, are dioecy, monoecy, heterostyly, dichogamy and incompatibility (self and cross). These barriers intervene not only in improvement process by making most of the crosses (on the basis of traits) problematic or rather impossible but also in achieving maximum productivity by hampering unimpeded pollination. The complete understanding of these mechanisms is mandatory for improvement as well as yield maximization in fruit crops. The present paper will stress upon one of the most prevalent crossing barrier systems in fruit crops i.e. dichogamy. As everyone know that most of the fruit crops produce hermaphrodite flowers. The efficiency of pollen removal and deposition of pollinators (Barrett, 2002) and reproduction assurance (Fenster and Marten-Rodriguez, 
2007) is enhanced with two sexes in one flower. Many floral attributes have been evolved to resolve male and female peculiarities within the same flower, some of these features are herkogamy (in which anther and pistil are spatially divided in the same flower) and dichogamy (temporal division in maturity of male and female parts). Dichogamy was first described by Kolreuter in 1761-1766 (Knuth, 1906), however, the term was coined by Sprengel in 1793 (Cetinbas and Unal, 2014). Dichogamy (from the Greek dicho- two pieces/ separated and gamous- marriage/ mating) is the maturation of male and female reproductive organs at different times in the course of reproduction period of a plant (Lloyd and Webb, 1986). In other words, it refers to anther dehiscence and pollen release occurring at different time than the attainment of receptivity of stigma in a flower of a species or among different flowers in diclinous species (Bertin, 1993). Generally, the term homogamy is being used when stamen and pistil attain the reproductive maturity at the same time, however, Lloyd and Webb (1986) also termed it as adichogamy (absence of dichogamy). Primarily, dichogamy appears to focus on preventing inbreeding depression by reducing self-fertilization and also play a role in promoting efficient pollen dispersal by reducing anther-stigma interference (Sargent et al., 2006). Dichogamy can be observed within a flower of a species as well as among different individuals in diclinous species (Bertin, 1993; Bertin and Newman, 1993). Dichogamy promotes outcrossing even in hermaphrodite species which controls genetic transmission within and among the population. While self-fertilization can be beneficial in certain cases, it has a limitation that by reducing the pollen flow within a population, it restricts gene migration and is more likely to express recessive or partially recessive deleterious mutations (Charlesworth et al., 1993). The fitness of the off-spring produced by selfing can, therefore, be lower than that of the off-spring produced through outcrossing. According to Bertin and Newman (1993) and Lloyd and Webb (1986), dichogamy is promoted by four primary factors as listed here under

Selection to avoid interaction between pollen and pistil

Selection to avoid self-fertilization

Selection for pollen discharge synchrony and stigma receptivity in different flower types of diclinous species

Optimal position for sending and receiving pollen.

\section{Types of dichogamy (Table1.)}

On the basis of evidences, Stout (1928), Faegri \& Pijl (1979) and Lloyd and Webb (1986) grouped dichogamy in 5 distinct classes.

\section{On the basis of order of presentation}

Protandry: It is a type of dichogamy in which anther matures before stigma during the period of reproduction or pollens are shed before the ovule matures. In Hazelnut, the cultivars like Palaz, Cakildak show protandry (Bostan, 2009). In macadamia nut the florets are protandrous and outcrossing increases nut yield (Howlett et al., 2015). Aonla also exhibits it as anther dehiscence starts with the flower opening where as stigma becomes receptive from second day of the anthesis (Saini and Sihag, 2020).

Protogyny: In this type, stigma matures before anther at the time of reproduction or pollens are shed after the maturation of ovule. In Cherimoya (Annona cherimola) flowers open and the stigma becomes receptive in the morning while the anthers do not mature and release pollen until the evening of the following day. This condition promotes 
outcrossing and requires hand pollination for good economic returns (Venkataratnam, 1959; Thakur and Singh, 1965; Richardson, 1996). In sapota the stigma comes out of the bud two days before the period of anthesis which reduces the sexual interference between anther and stigma and promotes outcrossing.

\section{On the basis of floral elements}

Intrafloral: Attainment of reproductive maturity of anther and stigma at different times within the single hermaphrodite flower is known as intrafloral dichogamy (Cetinbas and Unal, 2014).

Interfloral: This type of dichogamy is mostly seen in diclinous species where anther and stigma are in separate flowers. In this case, reproductive maturity is achieved at different times in the stamens and pistils of male and female flowers of dioecious or monoecious species (Cetinbas and Unal, 2014).

\section{On the basis of degree of stamen and pistil separation}

Complete: It is a type of dichogamy in which reproductive period of male and female do not overlap. In other words, the hermaphrodite flower enters in the first phase (either male or female) and then enters the second phase (other than the first phase) when only the first phase is over (Cetinbas and Unal, 2014). It always leads to complete outcrossing and prevents from inbreeding depression.

Incomplete: In this type of dichogamy, male and female reproductive phases overlap at a particular period. The overlap might be slight to total as per condition (Lloyd and Webb, 1986). For example, in passion fruit, three floral stages occur: in the first and the third, only the anthers can be contacted by the legitimate visitors while in the second, both the anthers and the stigmas are placed in the way of the pollinators (Amela García and Hoc, 2011). In passion fruit, incomplete protandry is observed and it takes 30 to 90 minutes for style deflection in the flowers towards lower position after opening of flower. Since pollen removal occurs throughout the day so there were chances of overlapping of pollen and stigma presentation (Dai and Galloway, 2010). It was also observed that delay of style deflection generated incomplete protandry (Lloyd and Webb, 1986; Dai and Galloway, 2010).

\section{On the basis of degree of plant synchronization}

Dichogamy may be grouped in various classes considering the synchronization of the flowers.

Asynchronous: The most common form, in this group, is asynchronous dichogamy (Webb and Bawa, 1983). In this case, pollen release in the flowers and the pollen acceptance phase of stigma occur at different times in each individual hermaphrodite flower or on inflorescence of a plant. In most species of such type the pollinator can carry pollen from a flower to another flower of same plant having receptive stigma, so geitonogamous self pollination and interference between androceium and gynoceium of different flowers can occur (Lloyd and Webb, 1986).

Hemi-synchronous: Hemi-synchronous dichogamy is a partial synchronization existed in a few or more flowers or in only a portion of inflorescence. In this, there is synchronization among the sex organs of the certain flowers, while there is no synchronization between these flowers and the sex organs of the rest of flowers (Lloyd and Webb, 1986).

Synchronous dichogamy: It occurs when all 
the flowers in an individual are in same phase. This form of dichogamy is also seen in Ziziphus mistol where there is a high synchrony in flowering between individuals, as well as in floral anthesis between/ within inflorescences within individuals was observed (Cerino et al., 2015). High protandrous synchronous dichogamy was observed among the flowers of Ziziphus mistol which prevented self pollination due to presence of complete intrafloral dichogamy. The plant is mainly cross pollinated and showed high seed set by the help of pollinators. Three floral phases were observed in Ziziphus mistol i.e. male phase, female phase and neuter phase respectively, sometimes due to overlapping of sexual phases within the inflorescence (neuter phase) geitonogamy occurs between the flowers (Cerino et al., 2015).

There are different subclasses of synchronous dichogamy depending on number of cycles and genetic features of flowers.

Multiple cycle: This is the most common type of synchronous dichogamy in which plant goes through various pollen-stigma cycles during flowering season. As in monoecious fig species individuals have several distinct crops of syconia per year (Wiebes, 1979; Janzen, 1979). In palm, only one inflorescence matures at a time (either protandrous or protogynous) or there may be two male periods and one female. In breadfruit (Artocarpus altitis), there are alternate phases of staminate and pistillate ones (Brantjes, 1981).

Duodichogamy: Duodichogamy was discovered by Stout (1928) in Castanea (Chsetnut). It is another form of synchronous dichogamy and consists of 1.5 cycles during a flowering season. 1.5 cycles refers to consecutive switches between 3 different phases i.e. male phase - female phase - male phase. In Chestnut, there are two types of inflorescences are seen- unisexual staminate catkins that develop on the previous seasson's shoot growth at the base of the flower branch and bisexual catkins that are found near the apex develop on current season's growth (Botta et al., 1995), the lower unisexual male catkin is the first start to open and the pistillate flower is next to open and not until 8-10 days after the anthesis of unisexual catkins, the male bisexual catkin flowers begin to open. The pistillate flowers become receptive during the interval between and at each end, slightly overlapping the periods that the two sets of catkins shed their pollens. Thus, the tree shows both protandrous and protogynous conditions in each flowering season. Similar pattern of flowering is also seen in a chinese tree i.e. Bridelia tomentosa (Lloyd and Webb, 1986).

One-cycle synchronous dichogamy: In single-cycle dichogamy, all pollen grains in a plant are released by the time the pistil reaches maturity, or vice versa. In other words, only one cycle occurs in the form of male to female or female to male. It is the second most common form of synchronous dichogamy after multi-cycle dichogamy. This form of dichogamy is seen in North temperate wind pollinated trees like elm, oak etc. (Llyod and Webb, 1986; Kerner, 1902; Knuth, 1906).

Heterodichogamy: Heterodichogamy is the least common form of synchronous dichogamy and has two genetic variants. Heterodichogamous species include two types of hermaphrodite flowers: protandrous and protogynous (Lloyd and Webb, 1986; Stout, 1928). During blooming time, the first type of flower remains in the male phase while the second type of flower is in the female phase. As the two flower morphs exhibit male and female functions at different times among individuals within a population, this phenomenon promotes outbreeding through 
enhanced intermorph pollination (Watanabe et al., 2015). It is further classified in to two subgroup i.e. heteromorphic and homomorphic (Llyod and Webb, 1986; Okazaki, 2010). In heteromorphic heterodichogamy, the opposite morphs, protandrous and protogynous, flowers open simultaneously as in walnut, hickories, hazelnut and pecannut (Asai, 2000; Renner, 2001; Kimura et al., 2003; Bai et al., 2006; Fukuhara and Tokumaru, 2014). In walnut, $J$. hindsii shows that the two mating types are reciprocal, so mating is incompletely disassortative (Gleeson, 1982). Pecannut exhibits two flowering type cultivars: Type-I protandrous (Cape Fear, Cherokee, Cheyenne, Desirable, Shepherd etc.) and Type II protogynous (Burkett, Candy, Forkert, Kanza, Stuart etc.) both are reciprocally compatible (Wood and Smith, 1997). In homomorphic heterodichogamy, the flowers of the two morphs open 6,12 , or 24 hour apart. In this case, one morph opens flower with receptive stigmas in the morning and produces pollen in the afternoon or the next morning, whereas the complementary morph opens flowers in the afternoon and sheds pollen in the following morning or afternoon as in Lauraceae (Stout, 1923 and Watanabe et al., 2015).

By the time interval between Stamen and Pistil emergence

The duration of time period by which the pollen and pistil emergence is separated such as in some tropical fruit crops like avocado (Persea americana) showing protogynous diurnally synchronous dichogamy having more than a day duration.

\section{Protogynous diurnally synchronous dichogamy in avocado}

A peculiar and interesting flowering behavior, protogynous diurnally synchronous dichogamy (PDSD) has been reported in avocado (Bergh, 1969). The flower is structurally bisexual, but functionally, it is unisexual. Each flower opens twice and closed in-between. The first time, it functions as female (receptive stigma), then the flower closes and reopens second time (next day) as male (dehiscence of anthers). The flower opening is so programmed that self pollination is completely eliminated within the group of cultivars, however, the flower is perfect and stigmas are receptive and pollens are being shed every day throughout the flowering season (Sharma, 2006). The avocado cultivars are categorized in two groups, i.e. type 'A' and type 'B', as per its unique floral behavior (Stout, 1923). In type ' $A$ ' the flower first opens as a female with a white receptive stigma in the morning then closes in late morning or early afternoon and remains closed until the afternoon of the following day when it opens as a male flower. Similarly in type ' $B$ ' the flower first opens as a female in afternoon of the first day, closes in the late afternoon and re-opens in the male phase the following morning (Table 2).

This diurnal synchrony helps in providing pollen (functional male), when a variety of other type is receptive (functional female). Therefore, pollination and fertilization between ' $A$ ' and 'B' types takes place. Bergh et al., (1969) reported approximately 40 per cent yield increase by the presence of adjacent second type cultivar.

Effect of temperature and humidity on stigma receptivity and anthesis in dichogamous fruit crops

Temprature and humidity are two most important factors for growth and periodicity of plants. It also plays a significant role in the timing and reproductive behaviour of fruit crops by influencing the stigma receptivity and anthesis. Yates and Sparks (1993) 
assessed the interaction of environmental factors like temperature and humidity on pollen dispersal and germination in pecannut cv. Desirable and Stuart. Anthers were detached and exposed to a relative humidity of $33,56,64$, and 97 per cent at 10, 21, 27 and $33^{\circ} \mathrm{C}$ temperatures, respectively. The results showed a significant increase in pollen release as the temperature increased and the relative humidity decreased. The results also indicated that the high relative humidity inhibited the anther dehiscence and it could be overcome by increased temperature where as low temperature also decreased anther dehiscence. Similar studies on influence of temperature and humidity on the stigma receptivity and anthesis in Annona cherimola was conducted by Lora et al., (2011) who observed that stigma receptivity became shorten with increase in temperature, however, it got extended due to high humidity. Results showed that flowers reached anthesis earliest at $20^{\circ} \mathrm{C}$ and $25^{\circ} \mathrm{C}$ and relative humidity between $80-90 \%$.

\section{Functions of dichogamy}

The widespread presence of dichogamy, i.e. a partial time-separation between male and female phases in fruit crops, is a longstanding issue in floral evolution. It plays an important role directly or indirectly in fruit production. Dichogamy affects sexual interference, floral longevity, pollen longevity, pollen load and yield.

\section{Avoidance of self-pollination and sexual interference}

It leads to the evolution of dichogamy. Avoidance of autogamy and geitonogamy depends on the form of dichogamy exhibited by the plant. It was found that complete intrafloral dichogamy exclusively avoids autogamy and to avoid geitonogamy synchronization in flowering should occur. Although in case of incomplete dichogamy the upshots will differ both for protandry and protogyny. Maturity of stigma before anther will increase the chances of cross pollination before selfing takes place but if anther matures before stigma there are more chances of anther to meet the stigma of the same flower and selfing may occur before crosspollination. Hence incomplete protogyny is more efficient in reducing self -fertilization than incomplete protandry (Lloyd and Webb, 1986).

Dai and Galloway (2010) observed that dichogamy reduced sexual interference and encouraged outcrossing in Passiflora incarnata. Style deflection occurs when half of the pollen is removed showing partial separation or incomplete protandry which is fortunate for pollen dispersal because there is no sexual interference until the style deflect to the lower position where it could interact with pollinators and can impede successful pollination.

Table.1 Different types of dichogamy in fruit crops

\begin{tabular}{|c|c|c|c|}
\hline Protandry & Protogyny & Heterodichogamy & Duodichogamy \\
\hline $\begin{array}{l}\text { Walnut, Aonla, } A \text {. } \\
\text { muricata, Hazelnut, } \\
\text { Ber, Macademia nut, } \\
\text { Pecanut, Passion fruit } \\
\text { (incomplete } \\
\text { protandry), Coconut }\end{array}$ & $\begin{array}{l}\text { Sapota, Fig, Banana, } \\
\text { Strawberry, } \\
\text { Pomegranate, Plum, } \\
\text { Annona spp. } \\
\text { Except A. muricata }\end{array}$ & $\begin{array}{l}\text { Walnut, Pecanut, } \\
\text { Pistachionut, } \\
\text { Ziziphus spina- } \\
\text { christi (Thorn } \\
\text { jujube) }\end{array}$ & $\begin{array}{l}\text { Chinese chestnut, } \\
\text { Bridelia tomentosa, } \\
\text { Cleistanthus collinus }\end{array}$ \\
\hline
\end{tabular}


Table.2 Sequential opening of avocado flowers for 'A' and 'B' types with important cultivars

\begin{tabular}{|c|c|c|c|c|c|}
\hline \multirow{2}{*}{$\begin{array}{l}\text { Flower } \\
\text { type }\end{array}$} & \multicolumn{2}{|c|}{ Day 1} & \multicolumn{2}{|c|}{ Day 2} & \multirow[t]{2}{*}{ Cultivars } \\
\hline & Morning & Afternoon & Morning & Afternoon & \\
\hline A & Female & - & - & Male & $\begin{array}{l}\text { Reed, Wurtz, Rincon, Hass, } \\
\text { Hazard, Lamb Anaheim, Gwen, } \\
\text { Lamb Hass, Pinkerton, Reed, } \\
\text { Simmonds, Perfecto, Pankay }\end{array}$ \\
\hline B & - & Female & Male & - & $\begin{array}{l}\text { Bacon, Ettinger, Fuerte, Nobel, } \\
\text { Sharwill, Shepard, Zutano } \\
\text { Bacon, Edranol , Nabal, Sir } \\
\text { Prize, Walter Hole, Queen, } \\
\text { Pollock, Panchoy }\end{array}$ \\
\hline
\end{tabular}

\section{Effect on floral longevity}

Floral longevity is defined as the length of time that the flower remains open and functionally active in the plant. Since floral longevity plays an important role in breeding methods and reproductive strategies in flowering plants, it is an important factor in attracting pollinators. It was found that that male duration as well as floral longevity was positively affected by the number of pollens where as number of ovules and female duration does not affect floral longevity in flowering plants (Marilaun, 1895 and Gao et al., 2015). This shows that dichogamous flowers live longer compared to adichogamous and male investment plays important role in it.

Ease in doing controlled and efficient pollination due to complete outcrossing

Dichogamy encourages outcrossing through temporary separation of male and female parts hence with the technique of controlled pollination it is easy to repair the crop load (Pinillos and Cuevas, 2008). As with Annona cherimoya, where protogynous dichogamy is demonstrated, hand pollination shows better results in fruit yield and quality (Richardson and Anderson, 1996).

\section{Prevalence of dichogamy}

Dichogamy is the most common mechanism which ensures cross pollination in fruit crops. However, if it is incomplete, it may allow some opportunity of self pollination by overlapping maturity of the flower flushes. As per literature available, Bertin and Newman (1993) reported that out of 4227 species of angiosperms, 3716 species show dichogamy (Sargent et al., 2006). It has also been observed that the flowers of dichogamous species are usually larger than adichogamous flowers. The exact frequency of dichogamy in fruit crops is still unknown, therefore, more attention and research are required which could provide additional knowledge about the flowering behaviour. Protandry is found to be the most common form of dichogamy in fruit crops where as protogyny is found to be common in wind, bee and fly pollinated flowers (Endress, 2010). Some sepcialised form of flowering behaviour such as heterodichogamy, duodichogamy and PDSD are also found in fruit crops. A form of protandrous-protogynous dimorphism has also been shown by some cultivars of walnut. Kumar (2017) reported that the cultivar 'Gobind' exhibited dimorphism as it was found to be homogamous in the first year and showed protogyny in the following year and was homogamous again in the third year, 
respectively while other cultivars like Payne, Blackmore, Hartley shows 100 per cent protandry in all three years under Kashmir conditions. Dichogamy has been found to be as widespread in both self-compatible and self-incompatible species as aonla being self incompatible shows protandry (Kishore, 2017) and plum shows protogyny (Sharma, 2006).

In conclusion the fruit crops, being mostly perennial, are highly heterozygous with complex genetic nature and several crossability barriers. Fruitfulness and improvement in fruit crops greatly rely upon their floral behaviour. Among the various evolutionary mechanisms in floral behaviour reported in fruit crops, dichogamy is one of the most important mechanisms with the most prevalent also. It refers to temporal variability in maturation of male and female reproductive organs. In this case, self pollination is prevented (partially or fully) in perfect flowered plants, due to maturity of two sex organs at different times. The comprehensive knowledge of it is mandatory for good fruit setting with quality and higher yield. The present paper reviewed the types and characteristics of dichogamy observed in various fruit crops. It will help in understanding the phenomenon of dichogamy in fruit crops and its further use in crop and yield improvement.

\section{References}

Ackerman, W. L. (1961). Flowering, pollination, self-sterility and seed development of Chinese jujube. Proceeding in American Society for Horticultural Science 77: 265-269.

Alexander, L.W and Woeste, K.E. (2016). Phenology, dichogamy and floral synchronization in a northern red oak (Quercus rubra) seed orchard. Canadian Journal of Forest Research
46: 629-636.

Amela Garcia, M.T and Hoc, P.S. (2011). Pollination mechanisms in Passiflora species: The common and the rare flowers-ecological aspects and implications for horticulture. In: Pollination: Mechanisms, Ecology and Agricultural Advances.

Asai, T. (2000). Dichogamy in fullmoon maple (Acer japonicum Thunb.). Bulletin of the Hokkaido Forestry Research Institute 37: 27-40. (In Japanese with English abstract.)

Asatryan, A and Tel-Zur, N. (2013). Pollen tube growth and self-incompatibility in three Ziziphus species. Flora 208: 390399.

Bai, W.N., Zeng, Y.F and Zhang, D.Y. (2007) Mating patterns and pollen dispersal in a heterodichogamous tree, Juglans mandshurica (Juglandaceae). New Phytologist 176: 699-707.

Bai, W.N., Zeng, Y.F., Liao, W.J and Zhang, D.Y. (2006). Flowering phenology and wind-pollination efficacy of heterodichogamous Juglans mandshurica (Juglandaceae). Annals of Botany 98: 397-402.

Barrett, S.C. (2002). The evolution of plant sexual diversity. Nature Reviews Genetics 3: 274-284.

Bergh, B.O. (1969). Avocado (Persea americana Mill). In: Outlines of perennial crop breedings in the tropics, F. P. Ferwerda and F. Wit, eds. Wageningen, Netherlands, p. 23-51.

Bertin, R.I and Newman, C.M. (1993). Dichogamy in angiosperms. Botanical Review 59(2): 112-152.

Bostan, S.Z. (2009). Phenological traits of important Hazelnut cultivars in ordu, Turkey. Acta Horticulturae 845: $207-$ 212.

Botta, R., Vergano, G., Me, G and Vallania, R. (1995). Floral Biology and Embryo Development in Chestnut (Castanea 
sativa Mill.). Hort Science 30: 12831286.

Brantjes, N.B.M. (1981). Nectar and the pollination of Bread fruit, Artocarpus Altilis (Moraceae). Acta Botanica Neerlandica 30: 345-352.

Bruckner, C.H., Casali, V.W.D., Moaraes, C.F., Ragazzi, A.J and Silva, E.M.A. (1995). Self incompatibility in passion fruit (Passiflora edulis Sims). Acta Horticulturae 370: 45-57.

Cerino, M.C., Richard, G.A., Torretta, J.P., Gutierrez, H.F and Pensiero, J.F. (2015). Reproductive biology of Ziziphus mistol Griseb (Rhamnaceae), a wild fruit tree of saline enviornments. Flora 211: 18-25.

Cetinbas, A and Unal, M. (2014) An Overview of Dichogamy in Angiosperms. Research in Plant Biology 4(5): 9-27.

Charlesworth, D., Morgan, M.T and Charlesworth, B. (1993). Mutation accumulation in finite outbreeding and inbreeding populations. Genetical Research 61: 39-56.

Clark, B.C., Partridge, L and Robertson, A. (1988) Frequency-Dependent Selection. Cambridge University Press: New York, NY, USA.

Cox, J.E. (1957). Flowering and pollination of passion fruit. Agricultural Gazette of New South Wales 68: 573-576.

Dai, C and Galloway, L.F. (2010). Do dichogamy and herkogamy reduce sexual interference in a self- incompatible species? Functional Ecology 25: 271-278

Endress, P.K. (2010). The evolution of floral biology in basal angiosperms. Philosophical Transactions of the Royal Society B: Biological Sciences 365: 411-421.

Faegri, K. and Pijl, L. (1979). The principles of pollination ecology, edition 3 . Oxford; New York: Pergamon Press.
Fenster, C.B and Marten-Rodriguez, S. (2007). Reproductive assurance and the evolution of pollination specialization. International Journal of Plant Sciences 168(2): 215-228.

Fukuhara, T and Tokumaru, S. (2013). Inflorescence dimorphism, heterodichogamy and thrips pollination in Platycarya strobilacea (Juglandaceae). Annals of Botany 113: 467-476.

Galil, J and Zeroni, M. (1967). On the pollination of zizyphus spina-christi (L.) Wild. in Israel. Israel Journal of Botany 16: 71-77.

Gao, J., Xiong, Y.Z and Huang, S.Q. (2015). Effects of floral sexual investment and dichogamy on floral longevity. Journal of Plant Ecology 8: 116-121.

Gleeson, S.K. (1982). Heterodichogamy in walnuts: Inheritance and stable ratios. Evolution 36: 892-902.

Glisic, I., Milatovic, D., Cerovic, R., Radicevic, S., Đorđevic, $\mathrm{M}$ and Milosevic, N. (2017). Examination of self-compatibility in promising plum (Prunus domestica L.) genotypes developed at the Fruit Research Institute, Cacak. Scientia Horticulturae 224: 156-162.

Howlett, B.G., Nelson, W.R., Pattemore, D.E and Gee, M. (2015). Pollination of macadamia: Review and opportunities for improving yields. Scientia Horticulturae 197: 411-419.

Janzen, D.H. (1979). How to be a Fig. Annual Review of Ecology, Evolution and Systematics 10: 13-51.

Kerner von Marilaun, A. (1895). The natural history of plants, their forms, growth, reproduction and distribution. New York: Henry Holt.

Kimura, M., Seiwa, K., Suyama, Y and Ueno, N. (2003). Flowering system of heterodichogamous Juglans 
ailantifolia. Plant Species Biology 18: 75-84.

Kishore, K. (2017). Phenological growth stages of Indian gooseberry (Phyllanthus emblica L.) according to the extended $\mathrm{BBCH}$ scale. Scientia Horticulturae 225: 607-614.

Knuth, P. (1906). Handbook of flower pollination (English translation), 3 volumes. London: Clarendon Press.

Kumar, A and Sharma, N. (2013). Protandrous-Protogynous dimorphism in indigenous selections from north western India and some exotic cultivars of Persian Walnut(Juglans regia L.). Advances in Horticultural Science 27: 61-66.

Lloyd, D.G and Webb, C.J. (1986). The avoidance of interference between the presentation of pollen and stigmas in angiosperms I. Dichogamy. New Zealand Journal of Botany 24: 135162.

Lora, J., Hormaza, J.I and Herrero, M. (2011). Stigmatic receptivity in a dichogamous early-divergent angiosperm species, Annona cherimola (Annonaceae): influence of temperature and humidity. American Journal of Botany 98(2): 265-274.

Luo, S., Zhang, D and Renner, S.S. (2007). Duodichogamy and androdioecy in the Chinese Phyllanthaceae Bridelia tomentosa. American Journal of Botany 94(2): 260-265.

McCarthy, B.C and Quinn, J.A. (1990). Reproductive ecology of system of two sympatric tree species. American Journal of Botany 77: 261-273.

Meena, A.K., Dutta, F., Marak, M.C and Pathak, P. (2017). Dichogamy in Fruit Crops. International Journal of Agriculture Innovations and Research 5(5): 889-890.

Okazaki, J. (2010). Sexual expression of plants and flowering phenology. The evolution of dichogamy. Phenology KENKYU 45: 1-6.

Pinillos, V and Cuevas, J. (2008). Artificial Pollination in Tree Crop Production. Horticultural Reviews 34: 239-276.

Renner, S.S. (2002). How common is heterodichogamy? Trends in Ecology and Evolution 16: 595-597.

Richardson, A.C and Anderson, P.A. (1996). Hand pollination effects on the set and development of cherimoya (Annona cherimola) fruit in a humid climate. Scientia Horticulturae 65:273-281.

Saini, R and Sihag, R.C. (2020). Flowering biology and phenology of aonla (Emblica officinalis Gaertn.) in the semi-arid environment of north-west India. International Journal of Agricultural Research 15: 1-8.

Sargent, R.D., Mandegar, M.A and Otto, S.P. (2006). A Model of the evolution of dichogamy incorporating sex-ratio selection, anther-stigma interference and inbreeding depression. Evolution 60: 934-944.

Sharma, R.R. (2006). Unfruitfulness in fruit plants: associated factors and measures of control (Chapter in book- Fruit Production: Problems and Solutions). International Book Distributing Company, pp. 3-32.

Stout, A.B. (1928). Dichogamy in flowering plants. Bulletin of Torrey Botanical Club 55: 141-153.

Thakur, D.R and Singh, R.N. (1965). Studies on pollen morphology, pollination and fruit set in some Annona. Indian Journal of Horticulture 22: 10-18.

Thompson, T.E and Romberg, L.D. (1985). Inheritance of heterodichogamy in pecanut. Heredity 76: 456-458.

Venkataratnam, L. (1959). Floral morphology and blossom biology studies on some Annonaceae. Indian Journal of Agricultural Sciences 29: 69-76.

Wajnberg. E., Tel-Zur, N., Shapira, I., 
Lebber, Y., Lev-Yadun, S., Zurgil, U., Reisman-Berma, $\mathrm{O}$ and Keasar, $\mathrm{T}$. (2019). Pollinator behavior drives sexual specializations in the hermaphrodite flowers of a heterodichogamous tree. Frontiers in Plant Science 10: 13-15.

Watanabe, S., Noma, $\mathrm{N}$ and Nishida, T. (2015). Flowering phenology and mating success of the heterodichogamous tree Machilus thunbergii Sieb. et Zucc (Lauraceae). Plant Species Biology 31: 29-37.

Webb, C.J and Bawa, K.S. (1983). Pollen dispersal by humming birds and butterflies: a comparative study of two low land tropical plants. Evolution 36: 1258-1270.

Webb, C.J and Lloyd, D.G. (1986). The avoidance of interference between the presentation of pollen and stigmas in angiosperms II. Herkogamy. New Zealand Journal of Botany 24: 163178.
Wester, P.J. (1910). Pollination experiments with Anonas. Bulletin of Torrey Botanical Club 37: 529-539.

Wiebes, J.T. (1979). Co-evolution of figs and their insect pollinators. Annual Review of Ecology and Systematics 10: 1-12.

Wood, M.N. (1934). Pollination and blooming habits of Persian walnut in California. US Department of Agriculture, Technical Bulletin No.387.

Wood, W.B., Smith, M.W., Worley, R.A., Anderson, P.C., Thompson, T.T and Grauke, L.J. (1997). Reproductive and vegetative characters of pecan cultivars. Hort Science 32:1028-1033.

Yates, I.E and Sparks, D. (1993). Environmental regulation of anther dehiscence and pollen germination in pecan. Journal of the American Society for Horticultural Science 118(6): 699706.

\section{How to cite this article:}

Prachi Pant, V. P. Singh, Rashmi Panwar and Rajkumar Jat. 2020. Dichogamy and its Relevance in Fruit Crops: An Overview. Int.J.Curr.Microbiol.App.Sci. 9(08): 698-708. doi: https://doi.org/10.20546/ijcmas.2020.908.076 